\title{
Stereospecific Group Transfer Polymerization of Methyl Methacrylate with Lewis-Acid Catalysis- Formation of Highly Syndiotactic Poly(methyl methacrylate)
}

\author{
Koichi Ute, ${ }^{\dagger}$ Hidetaka OHnuma, Itaru ShIMIZU, and Tatsuki Kitayama \\ Department of Chemistry, Graduate School of Engineering Science, Osaka University, Toyonaka 560-8531, Japan
}

(Received May 28, 2006; Accepted July 1, 2006; Published August 18, 2006)

\begin{abstract}
KEY WORDS Bulky Aluminum Lewis Acid / Trimethylsilyl Iodide / Bimodal Molecular Weight Distribution / Ketene Silyl Acetal / PMMA / Solubility / [doi:10.1295/polymj.PJ2006041]
\end{abstract}

Group transfer polymerization (GTP), disclosed in the early 1980's by Webster and co-workers, ${ }^{1}$ is one of the versatile living polymerizations for acrylic monomers. The GTP involves ketene silyl acetals as initiators and nucleophilic or Lewis acidic catalysts and has been claimed to proceed through migration or transfer of the silyl group to maintain ketene silyl acetal units at the propagating polymer chain-ends during the polymerization. The proposed mechanism of group transfer has urged several researchers to examine the stereochemistry of GTP with the expectation of any specific effects of the ketene silyl acetal ends on the stereochemical aspect of the propagation reaction, if the associative mechanism ${ }^{1-3}$ dominates the GTP. However, there had been no distinctive evidence of any special stereocontrol responsible to "group transfer", ${ }^{4-7}$ until we have reported a Lewisacid catalyzed GTP of methyl crotonate with $\mathrm{HgI}_{2}$ iodotrialkylsilanes $\left(\mathrm{R}_{3} \mathrm{SiI}\right)$ as catalysts, which produces disyndiotactic poly(methyl crotonate) (Scheme 1); the stereoregularity of the polymer depends on the structure of trialkylsilyl transferring groups..$^{8-11}$

During the investigation of Lewis-acid mediated stereoregulation of GTP, we found a stereospecific GTP of MMA catalyzed by aluminum phenoxide with $\mathrm{R}_{3} \mathrm{SiI}$ as a co-catalyst, which gives PMMA with a bimodal distribution of molecular weight (MW), the high MW fraction of which had high syndiotacticity (Scheme 2). Though the overall products had a lower syndiotacticity, it is evident that there exists highly syndiotactic-specific and highly active species in this GTP system.

\section{EXPERIMENTAL}

\section{Materials}

Methyl methacrylate was purified by fractional distillation under reduced nitrogen pressure, dried over calcium $\mathrm{CaH}_{2}$ and vacuum-distilled just before use. Dichloromethane and toluene were purified in the usual manner, dried over $\mathrm{CaH}_{2}$, and then vacuum distilled just before use. Iodotrimethylsilane $\left(\mathrm{Me}_{3} \mathrm{SiI}\right)$, bromotrimethylsilane $\left(\mathrm{Me}_{3} \mathrm{SiBr}\right)$, and chlorotrimethylsilane $\left(\mathrm{Me}_{3} \mathrm{SiCl}\right)$ purchased from Aldrich were used as received.

The ketene silyl acetal, 1-methoxy-1-(trimethylsiloxy)-2-methyl-1-propene (MTS), was prepared by the previously reported procedure ${ }^{9}$ from methyl $\alpha$ lithioisobutyrate, generated from methyl isobutyrate with lithium diisopropyl amide and $\mathrm{Me}_{3} \mathrm{SiCl}$.

All the aluminum phenoxides were prepared from the corresponding phenols and trialkylaluminums according to the literature. ${ }^{12}$ A typical procedure for the preparation of methylaluminum bis(2,6-di-tert-
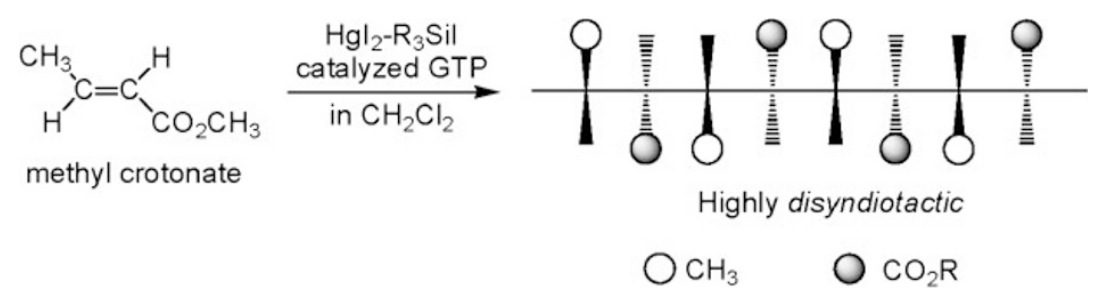

Scheme 1. Disyndiotactic-specific GTP of methyl crotonate.

${ }^{\dagger}$ To whom correspondence should be addressed (Tel: +81-6-6850-6231, Fax: +81-6-6841-1014, E-mail: ute@ chem.es.osaka-u.ac.jp). 


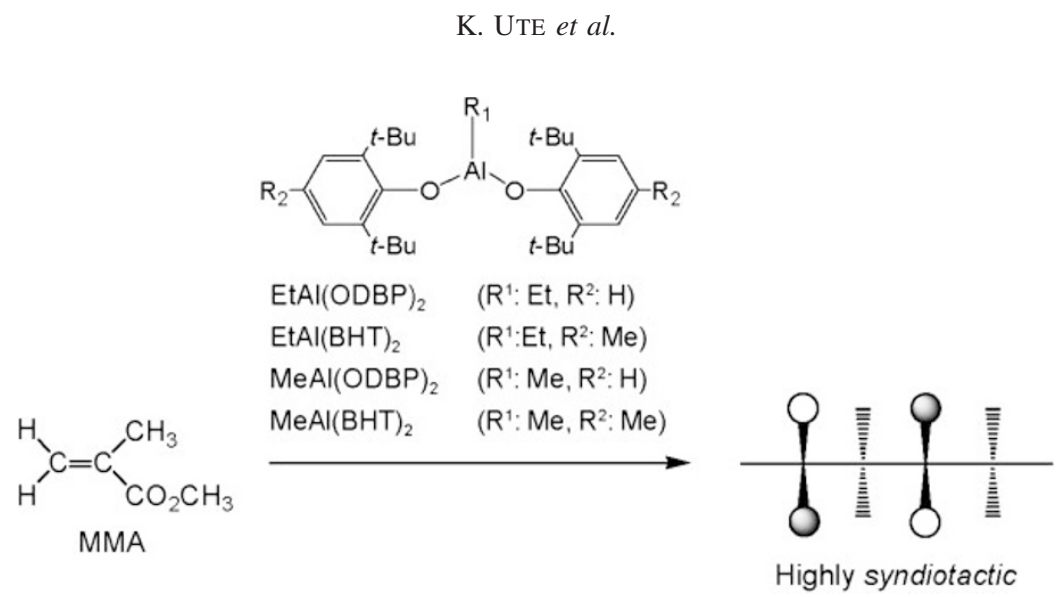

Scheme 2. Stereospecific GTP of methyl methacrylate.

Table I. GTP of MMA catalyzed by alkylaluminum bisphenoxide and $\mathrm{Me}_{3} \mathrm{SiI}$ in $\mathrm{CH}_{2} \mathrm{Cl}_{2}$ at $0{ }^{\circ} \mathrm{C}$ for $18 \mathrm{~h}^{\mathrm{a}}$

\begin{tabular}{|c|c|c|c|c|c|c|c|c|}
\hline \multirow{3}{*}{ Run } & \multirow{3}{*}{$\begin{array}{l}\text { Alkylaluminum } \\
\text { bisphenoxide }^{\mathrm{b}}\end{array}$} & \multicolumn{5}{|c|}{ Whole polymer } & \multicolumn{2}{|c|}{ Acetone-insoluble part } \\
\hline & & \multirow{2}{*}{$\begin{array}{c}\text { Yield } \\
\%\end{array}$} & \multirow{2}{*}{$\frac{M_{\mathrm{n}}{ }^{\mathrm{c}}}{10^{3}}$} & \multicolumn{3}{|c|}{ Tacticity $/ \%$} & \multirow{2}{*}{ Fraction $/ \%$} & \multirow{2}{*}{$r r / \%$} \\
\hline & & & & $\mathrm{mm}$ & $m r$ & $r r$ & & \\
\hline $1^{\mathrm{d}}$ & $\mathrm{EtAl}(\mathrm{BHT})_{2}$ & 1 & 128.2 & 2.3 & 12.2 & 85.5 & - & - \\
\hline 2 & $\operatorname{EtAl}(\mathrm{BHT})_{2}$ & 94 & 33.2 & 1.2 & 15.1 & 83.7 & 13 & 96.2 \\
\hline $3^{\mathrm{e}}$ & $\operatorname{EtAl}(\mathrm{BHT})_{2}$ & 21 & 190 & 1.6 & 9.8 & 88.6 & 33 & 98.7 \\
\hline 4 & $\operatorname{EtAl}(\mathrm{ODBP})_{2}$ & 59 & 44.4 & 1.5 & 19.6 & 78.9 & 4 & 95.6 \\
\hline 5 & $\operatorname{MeAl}(\mathrm{BHT})_{2}$ & 13 & 20.5 & 1.2 & 13.6 & 85.2 & 21 & 96.9 \\
\hline 6 & $\operatorname{MeAl}(\mathrm{ODBP})_{2}$ & 4 & 22.9 & 1.7 & 10.8 & 87.5 & 36 & 96.6 \\
\hline
\end{tabular}

${ }^{a}$ MMA $10 \mathrm{mmol}$, MTS $0.2 \mathrm{mmol}$, alkylaluminum bisphenoxide $0.15 \mathrm{mmol}, \mathrm{Me}_{3} \mathrm{Sil} 0.1 \mathrm{mmol}, \mathrm{CH}_{2} \mathrm{Cl}_{2} 4 \mathrm{ml}$. ${ }^{\mathrm{b}}$ See Scheme 2 for the abbreviations. ${ }^{\mathrm{c}}$ These polymers include high MW polymer whose MW exceeds a maximum porosity of the SEC columns $\left(3 \times 10^{6}\right)$. Thus, there is a possibility that the $M_{\mathrm{n}}$ values are underestimated. ${ }^{\mathrm{d}}$ Polymerization without $\mathrm{Me}_{3} \mathrm{SiI} .{ }^{\mathrm{e}}$ Polymerization at $-40{ }^{\circ} \mathrm{C}$ for $66 \mathrm{~h}$.

butylphenoxde) $\left[\mathrm{MeAl}(\mathrm{ODBP})_{2}\right]$ is as follows. A solution of 2,6-di-tert-butylphenol in toluene (2 equiv.) was added slowly to a toluene solution of trimethylaluminum ( 1 equiv.) at $0{ }^{\circ} \mathrm{C}$. The resulting mixture was stirred at room temperature for $20 \mathrm{~h}$. $\mathrm{MeAl}(\mathrm{ODBP})_{2}$ thus formed was purified in the following procedure. The solvent was removed under vacuum to leave a yellowish solid. The product was recrystallized three times by dissolving it in hot heptane and cooling to $-78^{\circ} \mathrm{C}$. After most of heptane was removed by a syringe and the residual heptane was evaporated under vacuum to dryness, the solid residue was dissolved in toluene and used for the polymerization reactions.

\section{Polymerization}

Polymerization was initiated by adding a solution of initiator in $\mathrm{CH}_{2} \mathrm{Cl}_{2}$ to a stirred mixture of monomer, aluminum phenoxide, cocatalysts and $\mathrm{CH}_{2} \mathrm{Cl}_{2}$ under a dry nitrogen atmosphere. The reaction mixture was homogeneous throughout the polymerization. After predetermined period of polymerization, a small amount of $\mathrm{HCl} / \mathrm{CH}_{3} \mathrm{OH}(\mathrm{ca} .1 \mathrm{M})$ was added to the mixture, and then the solution was poured into a large amount of hexane. The precipitated polymer was collected by filtration and dried at $40^{\circ} \mathrm{C}$ for $6 \mathrm{~h}$.

\section{Measurements}

Size exclusion chromatography (SEC) was performed on a JASCO PU-980 chromatograph equipped with Polymer Laboratories SEC columns PLgel Mixed-C $(7.5 \mathrm{~mm} \times 300 \mathrm{~mm} \times 2$, maximum porosity $3 \times 10^{6}$ ) and a JASCO RI-930 detector using $\mathrm{CHCl}_{3}$ as the eluent at $40^{\circ} \mathrm{C}$. Molecular weight was calibrated against standard PMMA samples (Shodex).

NMR spectra were recorded on a Varian UnityInova 500 or 750 spectrometer in $\mathrm{CDCl}_{3}$ at $55^{\circ} \mathrm{C}$. Differential scanning calorimetry (DSC) was performed on a RIGAKU DSC-8230 apparatus under nitrogen flow $(100 \mathrm{~mL} / \mathrm{min})$ at a heating rate of $10^{\circ} \mathrm{C} / \mathrm{min}$. The weight of the samples was $10 \mathrm{mg}$.

\section{RESULTS AND DISCUSSION}

GTP of MMA Catalyzed by Aluminum Phenoxide and $R_{3} \mathrm{SiI}$

The GTP of MMA was carried out in $\mathrm{CH}_{2} \mathrm{Cl}_{2}$ with MTS in the presence of several bulky aluminum Lewis acids, such as ethylaluminum bis(2,6-di-tertbutyl-4-methylphenoxide) [ $\left.\mathrm{EtAl}(\mathrm{BHT})_{2}\right]$, and $\mathrm{Me}_{3} \mathrm{SiI}$ at $0^{\circ} \mathrm{C}$ for $18 \mathrm{~h}$ (MMA:MTS:aluminum Lewis acid: $\left.\mathrm{Me}_{3} \mathrm{SiI}=100: 2: 1.5: 1\right) \quad$ (Table I, run 1). Without 


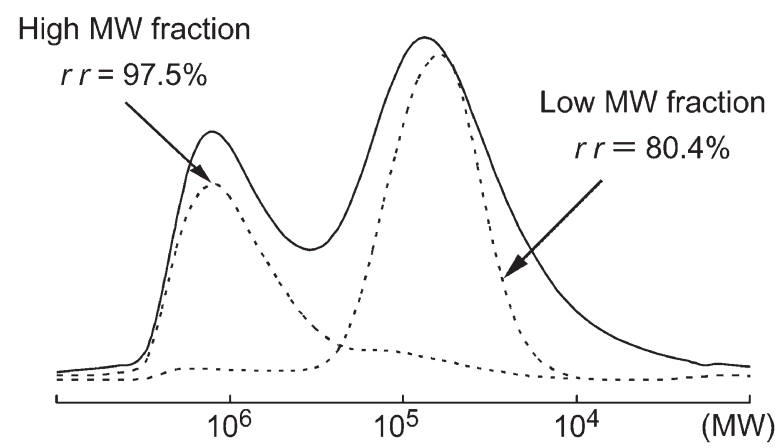

Figure 1. SEC curves of PMMA obtained by the GTP in the presence of $\mathrm{EtAl}(\mathrm{BHT})_{2}$ and $\mathrm{Me}_{3} \mathrm{SiI}$ in $\mathrm{CH}_{2} \mathrm{Cl}_{2}$ at $0{ }^{\circ} \mathrm{C}$ for $18 \mathrm{~h}$ (solid line). The SEC curves of the high and low MW parts fractionated by SEC are also shown (dotted line). MMA, $10 \mathrm{mmol}$; MTS, $0.2 \mathrm{mmol}$; EtAl(BHT) $)_{2}, 0.15 \mathrm{mmol}$; $\mathrm{Me}_{3} \mathrm{SiI}, 0.10 \mathrm{mmol}$.

$\mathrm{Me}_{3} \mathrm{SiI}$, a polymer yield was extremely low (ca. 1\%). The polymerization with $\operatorname{EtAl}(\mathrm{BHT})_{2}$ gave a predominantly syndiotactic PMMA in $94 \%$ yield. This PMMA had a bimodal distribution of MW. By means of SEC fractionation, the PMMA was separated into the high and low MW parts as shown in Figure 1. The high MW part had an apparent MW exceeding the maximum porosity of the SEC column $\left(3 \times 10^{6}\right)$, and the $r r$-triad content of this part was found to be $97.5 \%$ as determined by $750 \mathrm{MHz}{ }^{1} \mathrm{H}$ NMR spectroscopy. A similar GTP at $-40^{\circ} \mathrm{C}$ for $66 \mathrm{~h}$ also afforded a PMMA with a bimodal MW distribution in a lower yield (21\%). The high MW part isolated by SEC fractionation had an $r r$-content higher than $98.7 \%$ as estimated by $750 \mathrm{MHz}{ }^{1} \mathrm{H}$ NMR. This is the highest syndiotacticity reported so far for PMMA.

Figure 2 shows carbonyl ${ }^{13} \mathrm{C}$ NMR signals of the high and low MW parts of the PMMA obtained at $-40^{\circ} \mathrm{C}$. Very few stereochemical defect was observed for the high MW part even at heptad-level inspection. It seems evident that there exists at least two types of active sites with different activities and stereospecificities in this polymerization. Exchanging reactions of these sites must be negligible during the course of the GTP.

When $\operatorname{EtAl}(\mathrm{ODBP})_{2}, \quad \mathrm{MeAl}(\mathrm{BHT})_{2}$ or $\mathrm{MeAl}-$ $(\mathrm{ODBP})_{2}$ was used in place of $\mathrm{EtAl}(\mathrm{BHT})_{2}$, the yields of PMMA decreased in that order (Table I). All these PMMAs had bimodal MW distributions similar to that shown in Figure 1. As described in the following section, the high MW parts of the products are insoluble in acetone, and the high MW parts were isolated by precipitation into acetone and thus the ratios of the high and low MW parts in each PMMA were determined from the yields of the whole polymer and the acetone-insoluble polymer. Though the fraction of the acetone-insoluble high MW part depended on the structure of the $R_{1}$ and $R_{2}$ groups in aluminum bisphenoxides, the $r r$-contents of the high MW parts

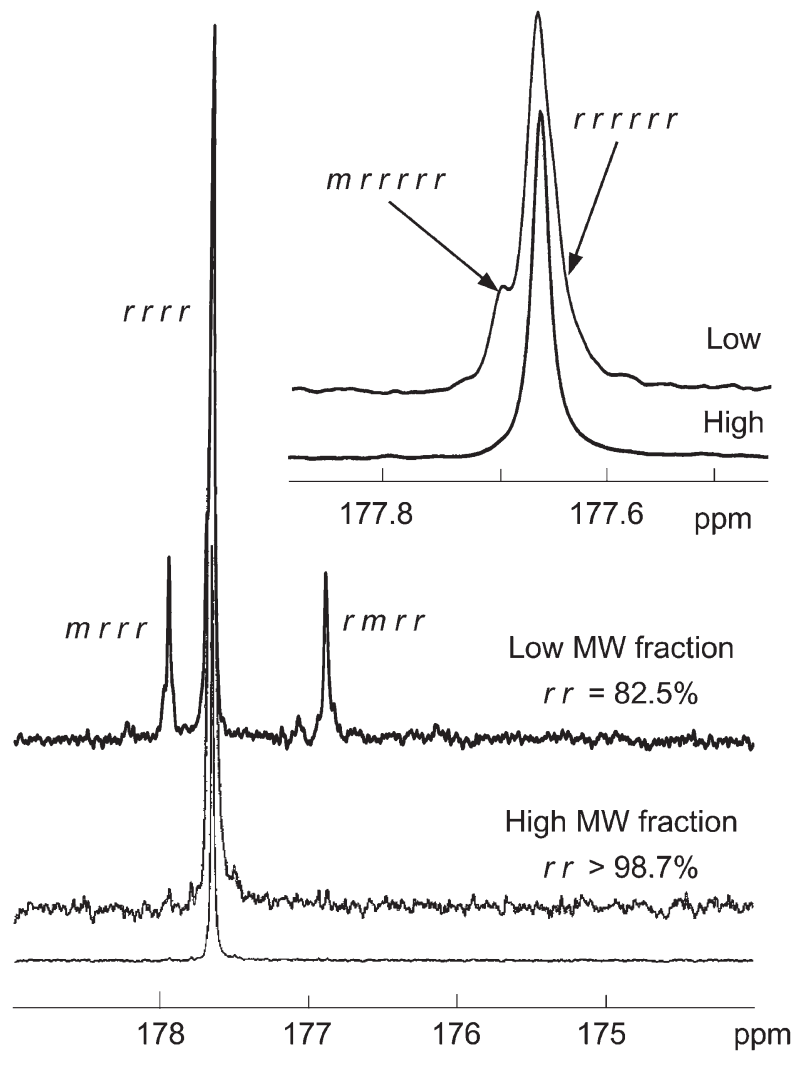

Figure 2. Carbonyl ${ }^{13} \mathrm{C}$ NMR spectra of high and low $\mathrm{MW}$ PMMAs obtained by $\operatorname{EtAl}(\mathrm{BHT})_{2}$-catalyzed GTP at $-40^{\circ} \mathrm{C}$ $\left(187.5 \mathrm{MHz}, 55^{\circ} \mathrm{C}, \mathrm{CDCl}_{3}\right)$.

were approximately $96 \%$ regardless of the structure of $R_{1}$ and $R_{2}$. The values are slightly lower than that for the PMMA obtained by SEC fractionation probably due to less effective removal of the low MW product by solvent fractionation.

The GTP of MMA was also investigated using $\mathrm{Me}_{3} \mathrm{SiCl}, \mathrm{Me}_{3} \mathrm{SiBr}$, or $\mathrm{Me}_{3} \mathrm{SiOTf}\left(\mathrm{OTf}: \mathrm{CF}_{3} \mathrm{SO}_{3}\right)$ in place of $\mathrm{Me}_{3} \mathrm{SiI}$ as a co-catalyst of $\mathrm{EtAl}(\mathrm{BHT})_{2}$ under the conditions described in Table I. The polymer yields decreased in the order, $\mathrm{Me}_{3} \mathrm{SiI}(94 \%)>$ $\mathrm{Me}_{3} \mathrm{SiBr}(41 \%)>\mathrm{Me}_{3} \mathrm{SiCl}(8 \%)$, and $\mathrm{Me}_{3} \mathrm{SiOTf}$ did not afford polymeric products.

\section{Properties of Highly Syndiotactic PMMA}

The high MW part showed different solubility from the low MW part. While the whole polymer was soluble in $\mathrm{CHCl}_{3}$, the high MW part was insoluble in acetone, THF and toluene, and the low MW part was soluble in these solvents. Thus, the high MW part could be isolated simply by pouring a $\mathrm{CHCl}_{3}$ solution of the bimodal PMMA into a large amount of these solvents. Figure 3 shows SEC curves of the resultant PMMAs before and after fractionation with toluene. The $r r$-content of the toluene-insoluble high MW part was slightly lower than that of the SEC-fractionated high MW part, probably due to less effective removal of the low MW product. 


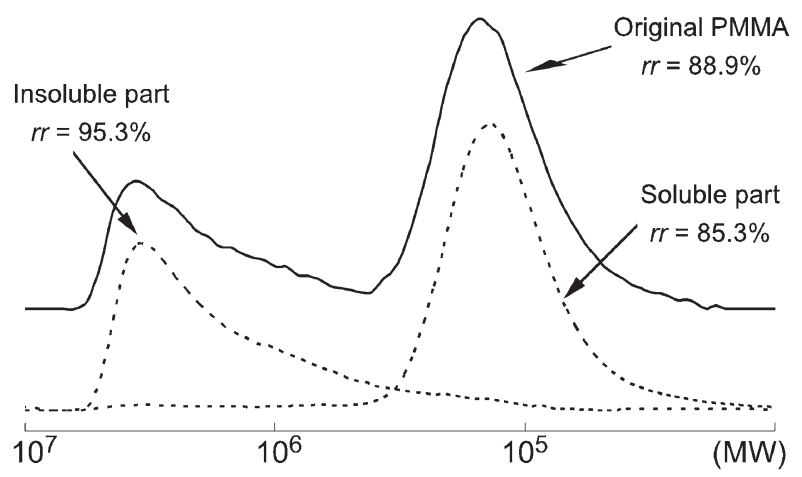

Figure 3. SEC curves of the PMMA obtained with MTS catalyzed by $\mathrm{MeAl}(\mathrm{BHT})_{2}$ and $\mathrm{Me}_{3} \mathrm{SiI}$ in $\mathrm{CH}_{2} \mathrm{Cl}_{2}$ at $-40{ }^{\circ} \mathrm{C}$, and the fractionated PMMAs with toluene.

The toluene-insoluble high MW PMMA showed glass transition temperature $\left(T_{\mathrm{g}}\right)$ at $131.2{ }^{\circ} \mathrm{C}$ by DSC analysis. This value is consistent with the $T_{\mathrm{g}}$ expected for highly syndiotactic PMMA: according to the literature, ${ }^{13} T_{\mathrm{g}}$ of PMMA with $M_{\mathrm{n}}>30,000$ increased with increasing syndiotacticity and can be extrapolated to be $131^{\circ} \mathrm{C}$ for $100 \%$ syndiotactic PMMA.

To examine whether the unusual solubility of the highly syndiotactic PMMA arises from high tacticity or high MW, the toluene-insoluble high MW PMMA was subjected to thermal degradation to obtain lower MW PMMA, since PMMA is known to undergo unzipping degradation upon thermal treatment. ${ }^{14,15}$ The thermal degradation of the PMMA $\left(M_{\mathrm{n}} \geq 507,000\right)$ was conducted at $340^{\circ} \mathrm{C}$ for $10 \mathrm{~min}$ under high vacuum, leaving the residual polymer with $M_{\mathrm{n}}$ of 52,000 in $15 \%$ yield, while the $r r$-triad content did not change (Figure 4). In spite of the much lower $M_{\mathrm{n}}$, the resultant syndiotactic PMMA was also insoluble in acetone, THF and toluene, indicating that the low solubility of the highly syndiotactic PMMA in various solvents is not due to the high MW but to its high stereoregularity.

\section{CONCLUSION}

Among the bulky aluminum Lewis acids and trimethylsilyl halides examined, the combination of $\mathrm{EtAl}(\mathrm{BHT})_{2}$ as the catalyst and $\mathrm{Me}_{3} \mathrm{SiI}$ as the co-catalyst gave the highest activity in the GTP of MMA with MTS in $\mathrm{CH}_{2} \mathrm{Cl}_{2}$. Though the whole products showed moderate syndiotacticity as well as a bimodal distribution of $\mathrm{MW}$, the high MW fractions were found to be highly syndiotactic, whose $r r$-triad content reached $98.7 \%$ after careful fractionation by SEC. The highly syndiotactic PMMA was also isolated more easily by solvent fractionation with acetone or toluene according to the distinct difference in solubility as compared with the low MW fraction, although the incomplete separation resulted in lower

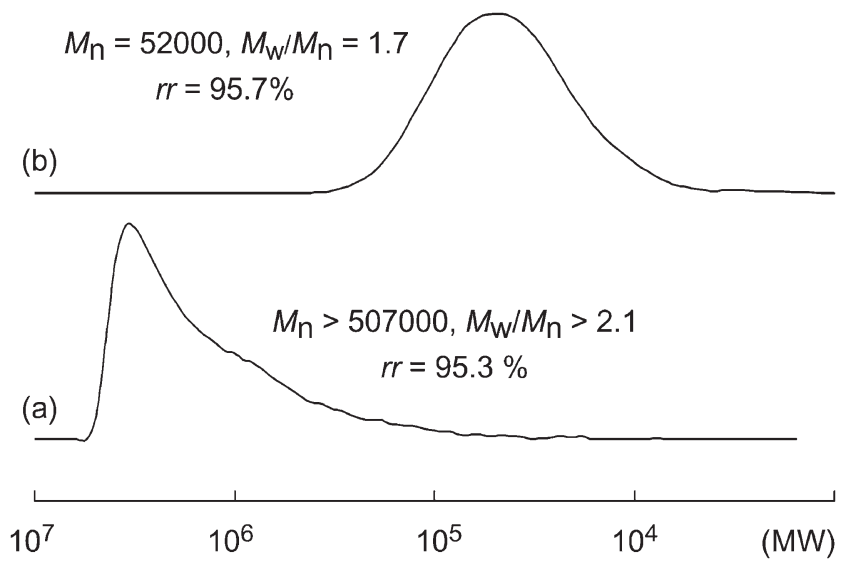

Figure 4. SEC curves of the highly syndiotactic PMMA (the toluene-insoluble fraction of the PMMA obtained by MeAl(BHT) $)_{2}-\mathrm{Me}_{3} \mathrm{SiI}$ catalyzed GTP in $\mathrm{CH}_{2} \mathrm{Cl}_{2}$ at $-40{ }^{\circ} \mathrm{C}$ ) before (a) and after (b) thermal degradation. The degradation of the PMMA $\left(60 \mathrm{mg}\right.$ ) was carried out in vacuo at $340^{\circ} \mathrm{C}$ for $10 \mathrm{~min}$ to leave $9 \mathrm{mg}$ of the residual PMMA.

value of $r r$-triad content (95-96\%). Since the number of active species responsible for the formation of the high MW polymers is expected to be extremely small, the identification of the putative initiating species to be generated in the system is still a challenge. As a preliminary experiment, the GTP with $\mathrm{B}\left(\mathrm{C}_{6} \mathrm{~F}_{5}\right)_{3}$, an effective Lewis acid for the GTP of acrylates, ${ }^{16}$ as an alternative to the aluminum phenoxides was carried out under otherwise same conditions, which gave PMMA with low syndiotacticity $\left(r r=70 \%\right.$ at $0^{\circ} \mathrm{C}$, $r r=86 \%$ at $-40{ }^{\circ} \mathrm{C}$ ) and narrow distribution of MW $\left(M_{\mathrm{w}} / M_{\mathrm{n}}=1.08-1.10\right)$. Thus, the aluminum phenoxide is expected to play a principal role in this high level of stereoregulation, possibly through coordination to the carbonyl group of MMA and the propagating species. On the other hand, the silyl iodide co-catalyst has been supposed to activate both initiator and growing chain-ends in the GTP. ${ }^{17,18}$

With our proceeding finding of stereospecific GTP of crotonates, ${ }^{10,11}$ the present GTP of MMA extends the possibility of stereocontrol in GTP through the use of appropriate Lewis-acid catalysts, though the highly syndiotactic PMMA is formed as a part of the whole product and, as a consequence, the fractionation process is inevitable as in the case of the early stage of isotactic-specific polymerization of propylene invented by Natta. ${ }^{19}$

However, distinctively different properties that the PMMA exhibits, such as high solvent-resistance, should be attractive both industrial and scientific viewpoints.

Acknowledgment. The authors thank Venture Business Laboratory of Osaka University for the use of the Varian Unity-Inova 750 spectrometer. 


\section{REFERENCES}

1. O. W. Webster, W. R. Hertler, D. Y. Sogah, W. B. Farnham, and T. V. Rajanbabu, J. Am. Chem. Soc., 105, 5706 (1983).

2. W. B. Farnham and D. Y. Sogah, Polym. Prepr., (Am. Chem. Soc., Div. Polym. Chem.), 27(1), 167 (1986).

3. D. Y. Sogah and W. B. Farnham, in "Organosilicon and Bioorganosilicon Chemistry," H. Sakurai, Ed., Wiley, New York, 1986, p. 219.

4. R. P. Quirk and G. P. Bidinger, Polym. Bull., 22, 63 (1989).

5. R. P. Quirk and J. Ren, Macromolecules, 25, 6612 (1992).

6. A. H. E. Müller, L. Lochman, and J. Trekoval, Macromol. Chem., 187, 1473 (1986).

7. M. A. Müller and M. Stickler, Makromol. Chem., Rapid Commun., 7, 575 (1986).

8. K. Ute, T. Tarao, and K. Hatada, Polym. J., 29, 957 (1997).

9. K. Ute, T. Tarao, S. Hongo, H. Ohnuma, K. Hatada, and T. Kitayama, Polym. J., 31, 177 (1999).

10. K. Ute, T. Tarao, S. Nakao, and T. Kitayama, Polymer, 44,
7869 (2003).

11. K. Ute, T. Tarao, and T. Kitayama, Polym. J., 37, 578 (2005).

12. A. P. Shreve, R. Mulhaupt, W. Fultz, J. Calabrese, W. Robbins, and S. D. Ittel, Organometallics, 7, 409 (1988).

13. H. Yasuda, H. Yamamoto, K. Yokota, S. Miyake, and A. Nakamura, Macromolecules, 26, 7134 (1993).

14. H. H. G. Jellinek, "Degradation of Vinyl Polymers," Academic Press, New York, 1955, p. 74.

15. K. Hatada, T. Kitayama, N. Fujimoto, and T. Nishiura, J. Macromol. Sci., A30, 645 (1993).

16. K. Ute, H. Ohnuma, and T. Kitayama, Polym. J., 32, 1060 (2000).

17. R. Zhuang and A. H. E. Müller, Macromolecules, 28, 8035 (1995).

18. R. Zhuang and A. H. E. Müller, Macromolecules, 28, 8043 (1995).

19. P. Pino and J. Natta, in "Present significance of his scientific contribution," S. Carra, F. Parisi, I. Pasquon, and P. Pino, Ed., Editorice di Chimica Sr1, 1982, p. 21. 